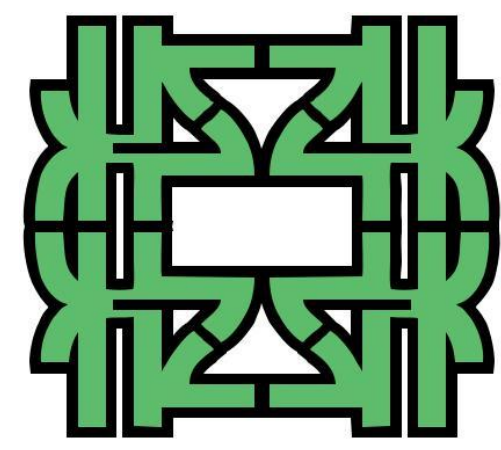

Aslan

KURIKULUM PENDIDIKAN VS KURIKULUM SINETRON

Wahyudin

KEPEMIMPINAN PERGURUAN

DALAM PERSPEKTIF TEORI INTERAKSIONISME SIMBOLIK

DAN DRAMATURGI 

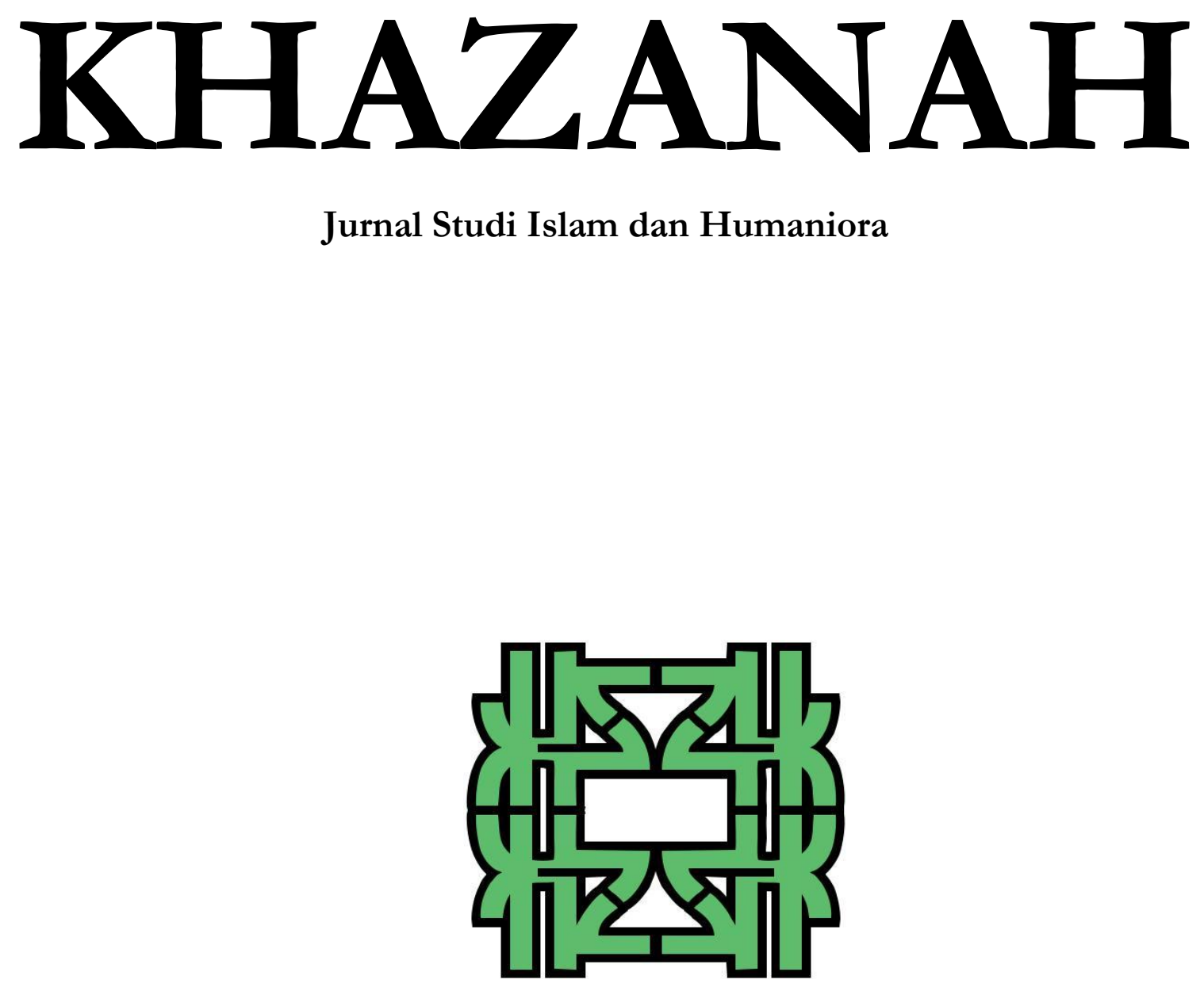
Volume XIV, Nomor 02, 2016

ISSN: 0215-837X E-ISSN ONLINE: 2460-7606

\section{EDITOR-IN-CHIEF}

Muhammad Zainal Abidin

\section{MANAGING EDITOR}

Anwar Hafidzi

\section{EDITORIAL BOARDS}

Mujiburrahman, (Antasari State Islamic University of Banjarmasin, Indonesia)

Syaifuddin Sabda, (Antasari State Islamic University of Banjarmasin, Indonesia)

Fathi Hasan Malkawi, (International Institute of Islamic Thought (IIIT), Amman, Jordan)

Masdar Hilmy, (Sunan Ampel State Islamic University of Surabaya, Indonesia)

Kautsar Azhari Noer, (Syarif Hidayatullah State Islamic University of Jakarta, Indonesia)

Zakiyuddin Baidhawy, (Salatiga State Islamic Institute, Indonesia)

Ahmad Rafiq, (Sunan Kalijaga State Islamic University of Yogyakarta, Indonesia)

\section{EDITORS}

Ammar Fauzi, (Sadra International Institute Jakarta)

Mujiburohman (Michigan State University, USA)

Najib Kailani (Sunan Kalijaga State Islamic University of Yogyakarta, Indonesia)

Wardani, (Antasari State Islamic University of Banjarmasin, Indonesia)

Muhammad Rusydi, (Antasari State Islamic University of Banjarmasin, Indonesia)

\section{EXECUTIVE EDITOR}

\section{Yokke Andini}

Wardatun Nadhiroh

Mohammad Iqbal Assyauqi

Mariatul Asiah 


\title{
KEPEMIMPINAN PERGURUAN \\ DALAM PERSPEKTIF TEORI INTERAKSIONISME SIMBOLIK DAN DRAMATURGI
}

\author{
Oleh: \\ Wahyudin \\ Universitas Islam Negeri Antasari Banjarmasin \\ E-mail: wahyubanjarmasin@gmail.com
}

\begin{abstract}
This paper focuses its discussion on the leadership of universities in the perspective of the theories of dramaturgy and symbolic interactionism. This study indicates that the dramaturgy concept underlines that the interaction between human beings is a covenant of agreed behaviour that can lead to the ultimate goal of the social interaction purposes. Role play is one tool that can refer to the achievement of the agreement. A tangible evidence that there is a role play in human life that can be seen in our own society. Man creates a separate mechanism by which he may perform as certain figures.
\end{abstract}

Abstrak: Tulisan ini membahas mengenai kepemimpinan perguruan tinggi dalam perspektif teori interaksionisme simbolik dan dramturgi. Penelitian ini menunjukkan bahwa konsep dramaturgi memahami interaksi antara manusia ada kesepakatan perilaku yang disetujui yang dapat mengantarkan kepada tujuan akhir dari maksud interaksi sosial tersebut. Bermain peran merupakan salah satu alat yang dapat mengacu kepada tercapainya kesepakatan tersebut. bukti nyata bahwa terjadi permainan peran dalam kehidupan manusia dapat dilihat pada masyarakat kita sendiri. Manusia menciptakan sebuah mekanisme tersendiri, dimana dengan permainan peran tersebut ia bisa tampil sebagai sosok- sosok tertentu.

Kata kunci: Perilaku, konsep, masyarakat, pemimpin, interaksi 


\section{Pendahuluan}

Saat ini Perguruan Tinggi Keagamaan Islam (PTKI) di Indonesia mendambakan Sebagai universitas riset (research university) menuju perguruan tinggi kelas dunia (world class university). Bahkan beberapa Universitas Islam Negeri (UIN) tengah berbenah menuju terwujudnya research univesity dan world class university tersebut dengan menggali dan memobilisir semua potensi yang dimiliki secara serius dan sistematis satu dasawarsa terakhir.

Sebagai sebuah perguruan tinggi, PTKI mengemban tiga tugas pokok, yaitu Pemerolehan atau penggalian pengetahuan (acquisition) pemindahan pengetahuan (transmission), dan penerapan pengetahuan (application) ${ }^{1}$. Jose Ortega Y. Gasset menegaskan bahwa tugas perguruan tinggi meliputi tiga hal yaitu, (1) transmisi budaya, (2) pengajaran tentang profesi, dan (3) penelitian ilmiah dan pelatihan untuk menyiapkan para ilmuan baru.

Membangun dan mengembangkan sebuah perguruan tinggi yang besar dan memiliki reputasi tinggi diperlukan perpaduan yang utuh dan kuat dari tiga konsep dasar, yaitu : nilai-nilai (values), sistem (system), dan kepemimpinan (leadership). Kepemimpinan (termasuk juga manajemen) merupakan Fondasi dari eksistensi sebuah perguruan tinggi yang memiliki implikasi yang luas dan sangat menentukan.

Oleh karena itu, tema sentral pengembangan perguruan tinggi sebenarnya terletak pada kepemimpinan (leadership), khususnya kepemimpinan akademik. menurut Selznik (1984), ${ }^{2}$ seorang pemimpin akademik harus memiliki kepekaan terhadap nilai-nilai dan harus beradaptasi dengan perubahan internal dan eksternal dalam organisasi. Bahkan kochan dan freeman (2012) menandaskan bahwa peran rektor selalu substantif dan simbolik. ${ }^{3}$

Guna mewujudkan sebuah perguruan tinggi yang memiliki reputasi tinggi, pimpinan perguruan tinggi harus memiliki sebuah sistem kepemimpinan yang efektif dengan core kepemimpinan akademik yang kokoh dengan integritas yang kuat. The

\footnotetext{
${ }^{1}$ Perkins, J.A. 1966. The University in Transtion. Princeton, New Jersey: Princton University Press.

2 Selznick, P. 1994. Leadership in administration A Socialogical Interpretation. Berkley, los Angeles, London: University of California Press.

${ }^{3}$ Freeman, S.J.R. \& Koehan, F.K. 2012.Academic Pathways to University Leadership President's Description Of Their Doctoral Educational. International Journal of Doctoral Studies, 7: 93-123.
} 
Carnegie Council on Policy Studies in Higher Education memberi rekomendasi kepada pimpinan perguruan tinggi untuk merencanakan masa depan dan membuat kebijakan-kebijakan yang menentukan perkembangan institusi, menyangkut : (1) peningkatan kualitas pengajar, penelitian dan pengabdian pada masyarakat; (2) mempertahankan keseimbangan esensial diantara para intlektual dalam usaha-usaha akademik menentang kekuatan pasar; (3) peningkatan integritas prilaku dalam kampus; (4) adaptasi secara efektif sehingga dapat menekan kerusakan sekecil mungkin dalam kehidupan intlekktual kampus; (5) melanjutkan penyesuai dinamis terhadap kemungkinan-kemungkinan baru tanpa menambah konpensasi sumber daya; (6) penggunaan sumber daya yang efektif dan pengalokasian internal sumber daya yang lebih baik; (7) menciptakan kondisi yang mendorong adanya kepemimpinan yang efektif; (8) memaksimalkan dana-dana swasta untuk menunjang perguruan tinggi; (9) mempertahankan sector swasta dari pendidikan tinggi dengan keutuhan ekonomi dan kebhinekaan (diversiy); (10) peningkatan kemampuan penelitian dalam perguruan tinggi; dan (11) memelihara kualitas kehidupan internal kampus . ${ }^{4}$

Perguruan tinggi sebagai sebuah organisasi, saat ini tidak lagi dipandang sematamata sebagai sebuah instrumen yang bersifat formal dan rasional yang sengaja Dibentuk sekedar untuk membantu manusia memenuhi kebutuhanya di bidang Pendidikan, melainkan dipandang sebagai makhluk hidup (living system) dan sebagai Sebuah masyarakat, dimana aspek kehidupan organisasi dan lingkungannya lebih mendapat perhatian. Di dalam organisasi perguruan tinggi terjadi interaksi sosial antara para anggota dan bertemu berbagai nilai dan budaya baru. Oleh karena itu, yang terjadi bukan hanya hubungan formal, melainkan lebih bersifat informal, emosional, dan kultural. ${ }^{5}$ Pergeseran dari pendekatan behavioristik yang lebih bersifat psychology approach kepada pendekatan mikro dalam sociology-antropology approach dalam melihat fenomen kepemimpinan pada purguruan tinggi menjadi sebuah keniscayaan guna menghasilkan horizon baru yang lebih luas dan komprehensif.

Dalam konteks inilah pengkajian tentang kepemimpinan perguruuan tinggi dipusatkan pada upaya mengidentifikasi bagaimana kepemimpinan perguruan tinggi

\footnotetext{
${ }^{4}$ Sonhadji, Ahmad. Manusia, Teknologi Dan Pendidkan Menuju Peradaban Baru. Malang: 2012. UM Press.

${ }^{5}$ Sobirin, A. 2009. Budaya Organisasi: Pengertian, Makna dan Aplikasinya dalam Kehidupan Organisasi. Yogyakarta: Unit Penerbit dan Percetakan Sekolah Tinggi Ilmu Menajemen YKPN.
} 
beroperasi dalam wajah eksistensial keperilakuan simbolis yang sarat dengan makna melalui interaksi organisasional. Disamping itu, secara komplementer dan integral fenomena kepemimpinan di perguruan tinggi tersebut dapat pula dimaknai sebagai sebuah konstruksi sosial dramaturgis, di mana para aktor memainkan manajemen. Pengaruh yang ditimbulkan dari interaksi sosial dalam sebuah perguruan tinggi.

\section{Kepemimpinan Perguruan Tinggi: Perspektif Teori Interaksionisme Simbolik dan Dramaturgi}

\section{Teori Interaksionisme Simbolik}

Teori interaksionisme simbolik pada awalnya berasal dari ide yang dikemukakan oleh George Herbert Mead, kemudian dimodifikasi dan diper-kenalkan oleh Herbert Blumer. ${ }^{6}$ Karakteristik dasar dari ide teori ini adalah suatu hubungan yang terjadi secara alami antara manusia dalam masyarakat dan hubungan masyarakat dengan individu. Interaksi yang terjadi antaa individu berkembang melalui simbol-simbol yang mereka ciptakan. Realitas sosial merupakan rangkaian peristawa yang terjadi pada beberapa individu dalam masyarakat. interaksi yang dilakukan antar individu itu berlangsung secara sadar. Interaksi simbolik juga berkaitan dengan gerak tumbuh, antara lain suara atau vocal, gerakan fisik ekspresi tubuh, yang semuanya itu mempunyai maksud dan disebut dengan "simbol".?

Ada enam proposisi utama dalam teori interaksionisme simbolik, yaitu: (1) Prilaku manusia mempunyai makna dibalik yang menggejala; (2) pemaknaan kemanusiaan perlu dicari sumber pada interaksi sosial manusia; (3) masyarakat merupakan proses yang berkembang holistik, tak terpisahkan tidak linier dan tidak terduga; (4) perilaku manusia itu berlaku berdasar penafsiran fenomenologik, yaitu berlangsung atas maksud, pemaknaan dan tujuan, bukan didasrakan atas proses mekanik dan otomatik; (5) konsep mental manusia itu berkembang dialektik; (6) perilaku manusia itu wajar dan konstruktif reaktif.

Sedangkan prinsip metodologi interaksi simbolik adalah sebagai berikut; (1) simbol dan interaksi itu menyatu. Tidak cukup bila kita hanya menekan fakta. Kita juga harus mencari yang lebih jauh yakni mencari konteks sehingga dapat ditangkap simbol dan

\footnotetext{
${ }^{6}$ Blumer H. 1969. Symbolik Interactionism Perspektif and Method. London: University of Calivornia Press Ltd.

${ }^{7}$ Basrowi, M. \& Soenyono. 2004. Teori Sosiologi Dalam Tiga Paradigma. Surabaya: Yayasan Kampusina.
} 
maknanya: (2) karena simbol dan makna itu tak lepas dari sikap pribadi maka jati diri subyek perlu ditangkap. Pemahaman mengenai konsep jati diri subyek yang demikian itu adalah penting; (3) peneliti harus sekaligus mengaitkan antara simbol dengan jati diri dengan lingkungan yang menjadi hubungan sosialnya. Konsep jati diri terkait dengan konsep sosiologi tentang struktur sosial dan lainya; (4) hendaknya direkam situasi yang menggambar simbol dan maknanya, bukan bukan hanya menekan fakta sensual saja; (5) metode-metode yang digunakan hendaknya mampu merefleksikan bentuk perilaku dan perosesnya; (6) metode yang di pakai handaknya mampu menangkap makna dibalik interaksi; (7) sensitizing yaitu sekedar mengarahkan pemikiran, itu yang cocok dengan interaksionisme simbolik, dan ketika mulai memasuki lapangan perlu dirumuskan menjadi yang lebih operasional, menjadi Scientific concepts. ${ }^{8}$

Menurt Herbert Blumer ${ }^{9}$, asumsi-asumsi interaksionisme simbolik meliputi: (1) Manusia bertindak terhadap sesuatu berdasarkan atas makna-makna yang dimiliki benda itu bagi mereka; (2) makna-makna itu merupakan hasil dari interaksi sosial dalam masyarakat manusia; (3) makna-makna dimodifikasi dan ditangani melalui sesuatu proses penafsiran yang digunakan oleh setiap individu dalam keterlibatanya dengan tanda-tanda yang dihadapinya.

Ide-ide dasar (roof images) interaksi simbolik yang dikembangkan oleh blumer diringkaskan penjelasanya oleh poloma (1979) sebagai berikut: (1) masyarakat terdiri dari manusia yang berinteraksi melalui tindakan bersama dan membentuk organisasi (struktur sosial); (2) interaksi terdiri atas berbagai tindakan manusia yang berhubungan dengan kegiatan manusia lain. Interaksi simbolik mencakup "penafsiran tindakan", sedangkan interaksi non simbolik hanya mencakup stimulus respon yang sifatnya sederhana; (3) obyek- obyek tidak memiliki makna yang intrinsik. Makna lebih merupakan produk interaksi simbolik; (4) manusia tidak hanya mengenal obyek eksternal (diluar dirinya), tapi bisa juga melihat dirinya sendiri sebagai obyek; (5) tindakan manusia adalah tindakan. Interpretatif yang di buat oleh manusia sendiri; (6) tindakan itu saling terkait

8 Basrowi, M. \& Soenyono. 2004. Teori Sosiologi Dalam Tiga Paradigma. Surabaya: Yayasan Kampusina.

9 Blumer H. 1969. Symbolik Interactionism Perspektif and Method.Englewood Cliffs, N.J. : Prentice- Hall, Inc. 
dan disesuaikan oleh anggota-anggota kelompok. Tindakan ini disebut tindakan bersama yang dibatasi sebagai "organisasi sosial dan perilaku tindakan berbagai manusia".

Pada dasarnya interaksi simbolik berlangsung diantara berbagai pemikiran dan makna yang melekat pada sebuah komunitas. Individu dan komunitas merupkan aktor, satu unit yang tidak dapat dipisahkan, saling menentukan satu sama lain. Tindakan individu adalah hasil dari "stimulus internal dan eksternal" atau dari "bentuk sosial diri dan komunitas"

Menurut Mead (1934) manusia mempunyai sejumlah kemungkinan tindakan dalam pemikiran sebelum ia memulai tindakan yang sebenarnya. Dalam proses mental yang tertutup yang mendahului proses tindakan yang sebenarnya. Berfikir, menurut Mead adalah suatu peroses individu berinteraksi dengan dirinya sendiri dengan mempergunakan simbol- Simbol yang bermakna.

Rose (dalam Ritzer, 1992), mensintesiskan asumsi-asumsi interaksionisme simbolik, yaitu: (1) Manusia hidup dalam suatu lingkungan simbol-simbol. Manusia yang memberi tanggapan terhadap simbol-simbol itu seperti juga ia memberi tanggapan terhadap rangsangan yang bersifat fisik. Pengertian dan penghayatan terhadap simbol-simbol yang tak terhitung jumlahnya itu merupakan hasil pelajaran dalam pergaulan hidup bermasyarakat; (2) Melalui simbol-simbl manusia berkemampuan menstimulir orang lain dengan cara- cara yang mungkin berbeda dari stimuli yang diterima dari orang lain itu; (3) Melalui komunikasi simbol-simbol dapat dipelajari sejumlah besar arti dan nilai-nilai, karena itu dapat dipelajari cara-cara tindakan orang lain; (4) Simbol, makna antara nilai-nilai yang berhubungan derngan mereka tidak hanya terpikir oleh mereka dalam bagian-bagian yang terpisah, tetap selalu dalam bentuk kelompok, yang kadang-kadang luas dan kompleks; dan (5) Berpikir merupakan suatu peroses pencarian yang bersifat simbolis dan untuk mempelajari tindakan-tindakan yang akan datang, menaksir keuntungan dan kerugian relatif menurut penilaian individual dimana satu diantaranya dipilih untuk dilakukan. ${ }^{10}$

${ }^{10}$ Ritzer, G. 1992. Sosiology: A Multiple Paradigm Science. Alih Bahasa. 


\section{Teori Dramaturgi}

Teori dramaturgi yang di cetuskan oleh Erving Goffman diilhami dan merupakan hasil pengembangan dari teori interaksionisme simbolik. Teori ini menjelaskan bahwa interaksi sosial dianalogkan (dimaknai sama) dengan pertunjukan teater atau drama diatas panggung. Manusia adalah aktor yang berusaha menggabungkan karakteristik personak dan tujuan kepada orang lain melalui " pertunjukan dramanya sendiri”. Manusia mengembangkan perilaku-perilaku yang mendukung perannya dalam mencapai tujuan. Identitas manusia tidak stabil dan setiap identitas merupakan bagian kejiwaan psikologi yang mandiri. Identitas manusia tergantung dari interaksi dengan orang lain.

Dalam perspektif dramaturgi Goffman, ketika manusia berinteraksi dengan sesamanya, ia ingin mengelola pesan yang diharapkan tumbuh pada orang lain terhadapnya. Untuk itu maka setiap orang melakukan pertunjukan bagi orang lain. Kaum dramaturgi panggung metaforis yang sedang memainkan peran-peran tertentu. Aksi sosial dipandang sebagai performa. Penggunaan simbol-simbol untuk menghadirkan sebuah cerita atau naskah bagi para penerjemah. Dalam peroses sebuah performa, arti dan aksi dihasilkan dalam sebuah adegan konteks sosiokultural.

Dalam perspektif dramaturgi, kehidupan ini dianalogkan sebagai teater. Interaksi sosial ibarat pertunjukkan diatas panggung yang di perankan oleh para aktor. Untuk memainkan peran, para aktor menggunakan bahasa verbal dan menampilkan perilaku non verbal tertentu yang menggunakan atribut-atribut sesuai dengan peran pada situasi sosial tertentu.

Menurut Goffman, panggung kehidupan sosial yang diperankan aktor terdiri dari wilayah depan (front region) dan wilayah belakang (back region). Wilayah depan merujuk kepada peristiwa sosial yang menunjukkan individu bergaya atau menampilakan peran formalnya. Mereka memainkan perannya di atas panggung sandiwara di hadapan khalayak penonton. Sedangkan wilayah belakang merujuk kepada tempat dan peristiwa mempersiapkan perannya di wilayah dua bagian, yakni: front pribadi (personal front) dan setting personal front mencakup bahasa verbal dan bahasa tubuh sang aktor. Sedang setting merupakan situasi fisik yang harus ada ketika aktor melakukan pertunjukan. Menurut Goffman, panggung depan 
mengandun anasir struktural, cenderung terlembagakan alias

mewakili kepentingan kelompok atau organisasi. ${ }^{11}$

Fokus perhatian dramaturgi sebenarnya bukan hanya individu, melainkan juga kelompok atau apa yang disebut tim. Selain memainkan peran dan karakter secara individu, aktor sosial juga berusaha mengelola kesan orang lain terhadap kelompoknya". Semua anggota

kelompok, baik keluarga, organisasi, partai politik, dan sebagainya disebut "tim pertunjukan" (performance team) yang mendramatisasikan suatu aktivitas. Kerjasama tim sering dilakukan oleh para anggota dalam menciptakan dan menjaga penampilan dalam wilayah depan.

Dalam perspektif dramaturgi, kehidupan ini ibarat teater, interaksi sosial mirip dengan pertunjukan di atas panggung yang menampilkan peran yang dimainkan para aktor. Untuk memainkan peran tersebut, biasanya sang aktor menggunakan bahasa verbal dan menampilkan perilaku non verbal tertentu serta mengenakan atribut-atribut tertentu, misalnya kendaraan, pakaian dan aksesoris lainya yang sesuai peranya dalam situasi tertentu. aktor harus memusatkan pikiran agar dia tidak keseleo lidah, mejaga kendali diri, melakukan gerak-gerik, menjaga nada suara, dan mengekspresikan sesuai dengan situasi.

Goffman membagi panggung depan menjadi dua bagian: front pribadi (personal Front) dan setting-nya terdiri atas alat-alat yang dianggap khalayak sebagai perlengkapan yang dibawa aktor kedalam setting, misalnya dokter diharapkan mengenakan jasa

dokter dengan stestoskop menggantung di lehernya. Personal front mencakup bahasa verbal dan bahasa tubuh sang aktor. Misalnya, berbicara sopan, pengucapan istilah-istilah asing, intonasi, postur tubuh, ekspresi wajah, pakaian, penampakan usia, dan sebagainya. Hingga derajat tertentu semua aspek itu dapat dikendalikan aktor. Ciri yang relatif tetap seperti ciri fisik, termasuk ras dan usia biasanya sulit disembunyikan atau diubah, namun aktor sering memanipulasinya dengan dengan menekankan atau melembutkannya, misalnya

\footnotetext{
${ }^{11}$ Goffman, E. 1956. The Presentation of Self in Everyday Life. Edinburgh : University of Edinburgh Sosial Science Research Centre.
} 
menhitamkan kembali rambut yang beruban dengan cat rambut. Sementara itu, setting merupakan situasi uban yang harus ada ketika aktor melakukan pertunjukkan, misalnya seorang dokter bedah memerlukan ruangan operasi, seorang supir taksi memerlukan kendaraan.

Panggung depan mengandung anasir struktural dalam arti bahwa panggung depan cenderung terlembagakan alias mewakili kepentingan kelompok atau organisasi. Sering ketika aktor melaksanakan peranya, peran tersebut telah ditetapkan lembaga tempat dia bernaung. meskipun berbau struktural, daya tarik pendekatan Goffman terletak pada interksi. Ia berpendapat bahwa umumnya orang-orang berusaha menyajikan diri mereka harus diidealisasikan dalam pertunjukan mereka di panggung depan, mereka bahwa mereka harus menyembunyikan hal-hal tertentu dalam pertunjukannya. Hal ini disebabkan oleh beberapa hal sebagai berikut:

1. Aktor munkin ingin menyembunyikan kesenangan-kesenanagan tersembunyi (misalnya meminum minuman keras sebelum pertunjukan)

2. Aktor mungkin ingin menyembunyikan kesalahan yang dibuat saat persiapan pertunjukan, langkah-langkah yang diambil untuk memperbaiki kesalahan tersebut (misalnya sopir taksi menyembunyikan fakta bahwa ia mulai salah arah)

3. Aktor mungkin merasa perlu menunjukan hanya peroduk akhir dan menyembunyikan peroses produksinya (misalnya dosen menghabiskan waktu beberapa jam untuk memberi kuliah, namun mereka bertindak seolah-olah telah lama memahami materi kuliah)

4. Aktor mungkin perlu menyembunyikan kerja kotor yang dilakukan untuk membuat produk akhir khalayak (kerja kotor itu mungkin meliputi tugas-tugas yang secara fisik kotor, semi dan menghina)

5. Dalam melakukan pertunjukan tertentu, aktor mungkin harus mengabaikan standar lain (misalnya menyembunyikan hinaan, pelecehan, atau perundangan yang dibuat sehingga pertunjukan dapat berlangsung). ${ }^{12}$

Aspek lain dari dramaturgi di panggung depan adalah aktor sering berusaha menyampaikan kesan bahwa mereka mempunyai hubungan khusus atau jarak sosial lebih dekat dengan khalayak dari pada jarak sosial yang sebenarnya. Goffman

\footnotetext{
${ }^{12}$ Ritzer, G. 1983. Contemporary Sosiological Theory. New York: Alfreda Knopt.
} 
mengakuai bahwa orang tidak selamanya ingin menunjukan peran formalnya dalam panggung depan. Orang mungkin memainkan suatu peran meskipun ia enggan akan peran tersebut atau menunjukan keengganan untuk memainkannya padahal ia senang bukan kepalang akan peran tersebut. Akan tetepi, menurut Goffman, keitka orang melakukan hal semacam itu, mereka tidak bermaksud membebaskan diri sama sekali dari peran sosial atau identitas mereka yang formal itu, namun karena ada perasaan sosial dan identitas lain yang menguntunkan mereka

Fokus perhatian Goffman sebenarnya bukan hanya individu, tetapi juga kelompok atau apa yang ia sebut tim. Membawakan peran dan karakter secara individu, aktor-aktor sosial juga berusaha mengelola kesan orang lain terhadap kelompoknya, baik itu keluarga, tempat bekerja. Partai politik, atau organisasi lain yang mereka wakili. Semua anggota tim itu oleh Goffman disebut tim pertunjukan (performance team) yang mendramatisasikan suatu aktivitas. Kerja sama tim sering dilakukan oleh para anggota dalam menciptaka dan menjaga penampilan dalam wilayah depan. Mereka harus mempersiapkan perlengkapan pertunjukan dengan matang dan jalannya pertunjukan, memainkan pemain inti yang layak, melakukan pertunjukan secermat dan seefisien dan kalau perlu juga memilih khalayak yang sesuai. Setiap anggota saling mendukung dan bila perlu memberi arahan lewat Isyarat non verbal, seperti isyarat dengan tangan atau isyarat mata agar pertunjukan berjalan mulus. ${ }^{13}$

Goffman (1956) menekankan bahwa pertunjukan yang dibawakan suatu tim sangat bergantung pada kesetiaan setiap anggotanya. Setiap anggota tim memegang rahasia tersembunyi bagi khalayak yang memungkinkan kewibawaan tim tetap terjaga. Dalam kerangka yang lebih luas, sebenarnya khalayak juga dapat dianggap sebagai bagian dari tim pertunjukan. Artinya, agar pertunjukan sukses, khalayak juga harus berpartisipasi mejaga agar pertunjukan secara keseluruhan berjalan lancar.

Dalam perspektif Goffman unsur penting lainya adalah pandangan bahwa interaksi mirip dengan upacara keagamaan yang sarat dengan berbagai ritual, aspekaspek "remeh" dalam perilaku yang sering luput dari perhatian orang merupakan bukti-bukti penting, seperti kontak mata antara orang-orang yang tidak saling mengenal

\footnotetext{
${ }^{13}$ Goffman, E. 1956. The Presentation of Self in Everyday Life. Edinburgh : University of Edinburgh Sosial Science Research Centre.
} 
di tempat umum. Bagi Goffman, perilaku orang-orang yang terlibat dalam interaksi yang sepintas tampak otomatis itu menunjukkan pola-pola tertentu yang fungsional. Perilaku saling melirik satu sama lain untuk kemudian berpaling lagi kearah lain menunjukkan bahwa orang-orang yang tidak saling mengenal itu menaruh kepercayaan untuk tidak saling mengganggu.

Bagi Goffman, tampaknya hampir tidak ada isyarat non verbal yang kosong dari makna. Isyarat yang tampak sepele pun, seperti "berpaling kearah lain", atau "menjaga jarak" dengan orang asing yang dimaksudkan untuk menjaga privasi orang lain adalah ritual antar pribadi atau dalam istilah Goffman menghargai diri yang "keramat". (sacred self), bukan sekedar adat kebiasaan. Tindakan-tindakan tersebut menandakan keterlibatan sang aktor

layak atau berharga sebagai manusia. Dengan demikian, penghargaan atas diri yang keramat ini dibalas dengan tindakanserupa sehingga berlangsung upacara kecil tersebut.

Kehidupan manusia tampak akan berjalan normal jika kita mengikuti ritual-ritual kecil dalam interaksi ini, meskipun kita tidak selamanya menjalankannya. Etiket adalah kata lain untuk ritual itu, yakni seperangkat penghargaan yang sama melandasi apa yang pantas dan tidak pantas kita lakukan dalam suatu situasi. Goffman menegaskan bahwa masyarakat memang memobilisasikan anggota-anggotanya untuk menjadi para peserta yang mengatur diri sendiri, yang mengajari kita apa yang harus dan tidak boleh kita lakukan dalam rangka kerjasama untuk mengkonstruksikan diri yang diterima secara sosial, salah satunya adalah lewat ritual. Menurut Goffman keterikatan emosional pada diri yang kita proyeksikan dan wajah kita merupakan mekanisme paling mendasari kontrol sosial yang saling mendorong kita untuk mengatur perilaku kita sendiri. Wajah adalah suatu citra diri yang diterima secara sosial. Menampilkan wajah yang layak adalah bagian dari tata karma situasional yaitu aturan-aturan mengenai kehadiran yang harus dikomunikasikan kepada orang lain yang juga hadir.

Untuk menunjukkan bahwa kita orang yang beradab, kita begitu peduli dengan tata karma sebelum kita melakukan sesuatu,tetapi ada kalanya kita melanggar etiket tersebut. Misalnya kita datang terlambat ke suatu pertemuan penting. Ketika kita menyadarinya, kita hampir selalu apa yang oleh Goffman disebut berbagai tindakan perbaikan (remedial work of various kind) yang fungsinya mengubah hal yang ofensif menjadi hal yang diterima. 
Teori ini melihat bahwa konstruksi relitas lahir melalui manajemen pengaruh yang ditimbulkan dari interaksi sosial. Sebagai sebuah drama, aktor yang terlibat dalam panggung interaksiter sebut memerankan tindakan yang telah tertata sebelumnya. Sedangkan jika terjadi krisis atau stuasi gawat maka untuk menyelamatkan pertunjukan (interaksi) terdapat atribut tertentu yang dijalankan.

Bila Aristoteles mengacu kepada teater maka Goffman mengacu pada pertunjukan sosiologis. Pertunjukan yang terjadi di masyarakat untuk memberi kesan yang baik untuk mencapai tujuan. Tujuan presentasi dari diri Goffman ini adalah penerimaan penonton akan manipulasi. Bila seorang aktor berhasil maka penonton akan melihat aktor sesuai sudut yang memang ingin diperlihatkan oleh aktor tersebut. Aktor akan semakin mudah untuk membawa penonton mencapai tujuan pertunjukan tersebut, ini dikatakan sebagai bentuk lain dari komunikasi.

Komunikasi sebenarnya adalah alat untuk mencapai tujuan. Bila dalam komunikasi konvensional manusia berbicara tentang bagaimana memaksimalkan indra verbal dan non verbal untuk mencapai tujuan akhir komunikasi dan agar orang lain mengikuti kemauan kita. Dengan demikian, dalam dramaturgi yang di perhitungkan adalah konsep menyeluruh bagaimana kita menghayati peran sehingga dapat memberikan feedback sesuai yang kita mau. Perlu diingat, dramaturgi mempelajari konteks perilaku dalam mencapai tujuannya dan bukan untuk mempelajari hasil dari perilakunya tersebut.

Dramaturgi memahami bahwa dalam interaksi antara manusia ada kesepakatan perilaku yang disetujui yang dapat mengantarkan kepada tujuan akhir dari maksud interaksi sosial tersebut. Bermain peran merupakan salah satu alat yang dapat mengacu kepada tercapainya kesepakatan tersebut. bukti nyata bahwa terjadi permainan peran dalam kehidupan manusia dapat dilihat pada masyarakat kita sendiri. Manusia menciptakan sebuah mekanisme tersendiri, dimana dengan permainan peran tersebut ia bisa tampil sebagai sosok-sosok tertentu.

Lingkup realitas sosial yang dikaji dalam dramaturgi ini merupakan lingkup sosial yang berskala kecil. Goffman menyatakan bahwa social establishment sebagai sistem tertutup; dalam arti Goffman hanya memperhatikan pertunjukan yang harus dimainkan saat itu saja, tanpa mempertimbangkan arti penting berbagai lembaga lain. 
Sebagai sebuah drama, perhatian utama dramaturgi pada proses interaksi sosial. Dalam interaksi sosial, aktor-aktor bertindak berdasarkan peran yang disandangnya (status) sehingga keotonoman aktor atau individu sangat bergantung dari peran rutin yang melekat dalam dirinya. Dramaturgi melihat diri sebagai produk yang ditentukan oleh situasi sosial. Seperti dalam drama, karakter di panggung merupakan produk dari naskahyang sebelumnya sudah diatur.

Goffman tidak memusatkan perhatiannya pada struktur sosial. Ia lebih tertarik pada interaksi tatap muka atau kehadiran bersama. Interaksi tatap muka itu dibatasinya sebagai individu-individu yang saling mempengaruhi tindaka-tindakan merekaa satu sama lain ketika masing-masing behadapan dengan fisik.

Individu diasumsikan selama kegiatan rutin akan mengetengahkan sosok dirinya yang ideal (sebagaimana yang dituntut oleh status sosialnya). Sebagaimana pemikiran Blumer, pemikiran Goffman melihat masyarakat terdirui atas kehidupan yang diliputi oleh berbagai tingkah laku. Goffman selalu memandang bahwa perilaku keseharian dan interaksi tatap muka diibaratkan sama dengan panggung teater/drama. Dalam pandangan Goffman mengasumsikan sebagai berikut.

a. Pusat interaksi adalah sumber informasi atau gambaran timbal balik (resiprokal).

b. Setiap individu membangun perilaku depan atau yang dimaknai tindakan individu yang secara teratur digunakan dalam kebiasan umum dan kebiasan khusus.bentuk depan ini dipengaruhi oleh latar belakang yang ada

c. Selama interaksi berlangsung, pelaku pada sebuah perstiwa akan memunculkan pengaruh dari pemain-pemain lain dengan cara tertentu

d. Perilaku depan ini dilembagakan; khususnya merujuk kepada peran-peran yang telah dibangun dengan baik

e. Terdapat dramatisasi dan direalisasikan dari perilaku depan yang dibangun

f. Perilaku interaksi (sebagai sebuah pertunjukan) tidak terpisahkan dari peran tingkah laku yang saling berhubungan dengan orang lain. Ketika seorang aktor saling berhubungan, ia membentuk sebuah tim atau susunan individu yang bekerja sama dalam mementaskan sebuah kebiasaan.

\section{A. Kepemimpinan PTKI di Kalimantan Selatan : Sekelumit Hasil Penelitian dan Justifikasi Teoritis}


Interaksi yang terbangun dalam proses kepemimpinan akademik pada PTKI yang memfungsikan secara dominan interaksi yang bersifat informal dengan dijiwai spirit dan nilai-nilai kekeluargaan, kebersamaan, dan religiusitas dengan simbol-simbol verbal dan non-verbal yang dibalut secara halus dengan budaya organisasi secara spesifik telah memuat makna persaudaraan, persatuaan, dan pengabdian kepada tuhan secara harmonis dalam rangka menjaga keseimbangan (equilibrium) kosmis. Konsep sosiobudaya setempat (Banjar) tentang "bubuhan" (papadara)", " mengayuh jukung baimbai" dan "hidup batuah lawan babarakat" telah menjadi landasan maknawi dalam fenomena kepemimpinan akademik pada PTKI".

Dalam peroses kepemimpinan akademik pada PTKI, peran aktor pemimpin terutama pemimpin puncak (Rektor atau Ketua) sangat sentral dan urgen. Figur pemimpin organisasi PTKI yang tenang, kalem, halus, akrab, dan kebapaan serta telah mewujudkan suasana interaksi yang senyap dan stabil. situasi ini melanggengkan pengaruh kepemimpinan beroprasi dalam menggerakkan sumber-sumber insani organisasi. Penampakan karakteristik individual pemimpin tersebut merupakan wujud perilaku simbolik yang memberi makna khas yang ditangkap komunitas interaksi kepemimpinan. Makna yang dihayati anggota komunitas (bawahan) adalah sebagai pelindung, pengayom, bahkan patner dalam kehidupan organisasional. pola interaksi informal yang hangat, akrab dan cair yang dilakukan oleh pemimpin PTKI terhadap bawahanya dengan dibingkai perilaku-perilaku simbolis seperti "bajajalanan", "bajanguk", "batatakunan", dan "bapapandiran" mengandung makna kesetiaan, solidaritas dan kekerabatan (persaudaraan) yang unik. Dalam meneguhkan legalitas dan pengakuan kepemimpinan, pemimpin PTKI tetap memfungsikan media komunikasi sosial berupa rapat yang telah di perhalus dengan semangat kekeluargaan dalam rangka mendapat sosio-politik komunitas organisasi.

Nilai-nilai dan filosofi sosial yang dianut oleh komunitas organisasi PTKI telah membentuk wajah eksistensial bagi organisasi, serta berfungsi menjadi perekat dan pondamen yang kokoh dalam keberlangsungan organisasi. Nilai-nilai tersebut meliputi: nilai kekeluargaan, nilai kebersamaan dan nilai religiusitas Islam; serta filosofi yang meliputi: religius (teologis dan ritual), ikhlas, keperluan sosial (filantropi), pengabdian (ibadah), dan keridhaan Allah. Nilai nilai dan filosofi sosial yang melandasi 
kepemimpinan akademik pada PTKI ini merupakan perwujudan makna essensial berdimensi kehidupan sosial, religius,serta berdimensi sosial-spiritual. Merupakan pesan simbolis primordial kehidupan organisasional PTKI.

konstruksi simbolik yang direpresentasikan pada objek formal organisasi berupa lambang (logo) institusi yang di visualisasikan ke dalam tiga elemen dasar berupa masjid, kitab suci dan pena, memuat konstruksi makna sebagai lembaga pendidikan tinggi Islam mengemban amanah untuk mengaktualisasikan pesan-pesan Al-quran (nilai-nilai Islam) guna membangun peradaban Islam.pesan simbolik ini sayangnya kurang di pahami, diresapi, dan dihayati dalam peroses kepemimpinan akademik pada PTKI. Sehingga peroses tranformasi organisasi kurang terlucut dengan baik.

Berdasaran interpretasi teoritis empirik tersebut maka sintesis teoritis dapat dijustifikasikan dari perspektif teori interaksionisme simbolik dan dramaturgi yang melandasinya. Karakteristik dasar dari ide teori ini adalah suatu hubungan yang terjadi secara alami antara manusia dalam masyarakat dan hubungan masyarakat dengan individu. interaksi yang terjadi antar individu berkembang melalui simbol-simbol yang mereka ciptakan. Realitas sosial merupakan rangkaian meristiwa yang terjadi pada beberapa individu dalam masyarakat. Interaksi yang dilakukan antar individu itu berlangsung secara sadar.interaksi simbolik juga berkaitan dengan gerak tubuh, antara lain suara atau vokal, gerakan fisik ekspresi tubuh, yang semuanya itu mempunyai maksud dan disebut dengan "simbol". ${ }^{14}$

Enam proposisi utama dalam teori interakpsionisme simbolik, yaitu(1) perilaku manusia mempunyai makna dibalik yang menggejala; (2) pemaknaan kemanusiaan perlu dicari sumber pada interaksi sosial manusia; (3) masyarakat merupakan peroses yang berkembang holistik, tak terpisah tidak linier dan tidak terduga; (4) perilaku manusia itu berlaku berdasarkan penafsiran fenomenologik, yaitu berlangsung atas maksud, pemaknaan dan tujuan, bukan didasarkan atas proses mekanik dan otomatik; (5) konsep mental manusia itu berkembang dialektik; (6) perilaku manusia itu wajar dan konstruktif reaktif.

\footnotetext{
${ }^{14}$ Basrowi, M. \& Soenyono. 2004. Teori Sosiologi Dalam Tiga Paradigma. Surabaya: Yayasan Kampusina. H. 95.
} 
Menurut Herbert Blumer (1966), asumsi-asumsi interaksionisme simbolik meliputi: (1) manusia bertindak terhadap sesuatu berdasrkan atas makna-makna yang dimiliki benda itu bagi mereka; (2) makna-makna itu merupakan hasil dari interaksi sosial dalam masyarakat manusia; (3) makana-makna dimodifikasi dan di tangani melalui suatu peroses penafsiran yang digunakan oleh setiap individu dalam keterlibatannya dengan tanda-tanda yang dihadapinya.

Ide-ide dasar (roof images) interaksi simbolik yang dikembangkan oleh Blumer diringkaskan penjelasnnya oleh Poloma (1979) sebagai berikut: ${ }^{15}$ (1) masyarakat terdiri dari manusia yang berinteraksi melalui tindakan bersama dan membentuk organisasi (struktur sosial); (2) interaksi terdiri atas berbagai tindakan manusia yang berhubungan dengan kegiatan manusia lain. Interaksi simbolik mencakup "penafsiran tindakan", sedangkan interaksi non simbolik hanya mencakup stimulus respon yang sifatnya sederhana; (3) obyek- obyek tidak memiliki makna yang intrinstik. Makna lebih merupakan peroduk interaksi simbolik; (4) manusia tidak hanya mengenal obyek eksternal (diluarnya dirinya), tapi bisa juga melihat dirinya sendiri sebagai obyek; (5) tindakan manusia adalah tindakan, Interpretatif yang dibuat oleh manusia sendiri; (6) tindakan itu saling terkait dan disesuaikan oleh anggota-anggota kelompok. Tindakan ini disebut tindakan bersama yang dibatasi sebagai "organisasi sosial dan perilaku tindakan berbagai manusia”.

Pada dasarnya interaksi simbolik berlangsung diantara berbagai pemikiran dan makna yang melekat pada sebuah komunitas. Individu dan komunitas merupakan aktor, satu unit yang tidak dapat dipisahkan, saling menentukan satu sama lain. Tindakan individu adalah hasil dari "stimulus internal dan eksternal" atau dari "bentuk sosial diri dan komunitas". Selain itu, interprretasi terhadap fenomena kepemimpinan akademik pada PTKI juga dapat dilihat dari teori dramaturgi. Teori ini merupakan peri teori interaksionisme simbolik.

Teori ini menjelaskan bahwa interaksi sosial dianalogkan (dimaknai sama) dengan pertunjukkan teater atau drama diatas panggung. Manusia adalah aktor yang berusaha menggabungkan karakteristik personal dan tujuan kapada orang lain

\footnotetext{
${ }^{15}$ Poloma, M.M. 2000. Sosiologi Kontemporer. Jakarta: Raja Grafindo Persada.
} 
melalui "pertunjukan dramanya sendiri". Manusia mengembangkan perilaku-perilaku yang mendukung perannya dalam mencapai tujuan. Identitas manusia tidak stabil dan setiap identitas merupakan bagian kejiwaan psikologi yang mandiri. Identitas manusia tergantung dari interaksi dengan orang lain.

Dalam prespektif dramturgi Goffman, ketika manusia berinteraksi dengan sesamanya, ia ingin mengelola pesan yang diharapkan tumbuh pada orang lain terhadapnya. untuk itu maka setiap orang melakukan pertunjukan bagi orang lain. Kaum dramaturgi panggung sebagai performa. Pengguna simbol-simbol untuk menghadirkan sebuah cerita atau naskahbagi para penerjemah. Dalam sebuah performa, arti dan aksi dihasilkan dalam sebuah adegan konteks sosiokultural.Dalam prespek dramaturgi, kehidupan ini dianalogkan sebagai teater. Interaksi sosial ibarat pertunjukan di atas panggung yang diperankan oleh para aktor. Untuk non-verbal tertentu yang menggunakan atribut-atribut sesuai dengan peran pada situsi sosial tertentu.

Menurut Goffman, panggung kehidupan sosial yang diperankan aktor terdiri dari wilayah depan (front region) danwilayah belakang (back region). Wilayah depan merujuk kepada peristiwa sosial yang menunjukkan bahwa individu bergaya atau menampilkan peran formalnya. Mereka memainkan perannya di atas panggung sandiwara di hadapan khalayak penonton. Sedangkan wilayah belakang merujuk kepada tempat dan peristiwa mempersiapkan perannya diwilayah dua bagian, yajkni: front pribadi ( personal front) dan setting personal front mencakup bahasa verbal dan bahasa tubuh sang aktor. Sedangkan setting merupakan situasi fisik yang harus ada ketika aktor melakukan pertunjukan. Menurut Goffman, panggung depan mengandung anasir struktural, cenderung terlembaga alias mewakili kepentingan kelompok atau organisasi.

Goffman mengakui bahwa panggung depan mengandung anasir struktural dalam arti bahwa panggung depan cenderung terlembagakan alias mewkili kepentingan kelompok atau organisasi tempat dia bernaung. Meskipun berbau struktural, daya tarik pendekatan Goffman terletak pada interaksi. Ia berpendapat bahwa umumnya orangorang berusaha menyajikan diri mereka yang diidealisasikan dalam pertunjukan mereka di panggung depan, merasa bahwa meraka harus menyembunyikan hal-hal tertentu dalam pertunjukan. 
Goffman menekankan bahwa pertunjukan yang dibawakan suatu tim sangat bergantung pada kesetiaan setiap anggotanya. Setiap anggota tim memegang rahasia tersembunyi bagi khalayak yang memungkinkan kewibawaan tim tetap terjaga. Dalam kerangka yang lebih luas, sebenarnya khalayak juga dapat dianggap sebagai bagian dari tim pertunjukan. Artinya, agar pertunjukan sukses, khalayak juga harus berpartisipasi mejaga agar pertunjukan secara keseluruhan berjalan lancar.

Dalam perspektif Goffman unsur penting lainya aadalah pandangan bahwa interaksi mirip dengan upacara keagamaan yang sarat dengan berbagai ritual, aspekaspek "remeh" dalam perilaku yang sering luput dari perhatian orangmerupakan bukti-bukti penting, seperti

kontak mata antara orang-orang yang tidak saling mengenal di tempat umum. Bagi Goffman, perilaku orang-orang yang terlibat dalam interaksi yang sepintas tampak otomatis itu menunjukkan pola-pola tertentu yang fungsional. Perilaku saling melirik satu sama lain untuk kemudian berpaling lagi kearah lain menunjukkan bahwa orang-orang yang tidak saling mengenal itu menaruh kepercayaan untuk tidak saling mengganggu.

Teori ini melihat bahwa konstruksi relitas lahir melalui manajemen pengaruh yang ditimbulkan dari interaksi sosial. Sebagai sebuah drama, aktor yang terlibat dalam panggung interaksit tersebut memerankan tindakan yang telah tertata sebelumnya. Sedangkan jika terjadi

Krisis atau stuasi gawat maka untuk menyelamatkan pertunjukan (interaksi) terdapat atribut tertentu yang dijalankan.

\section{Kesimpulan}

Kesimpulan dari tulisan ini menunjukkan bahwa teori dramaturgi memahami bahwa dalam interaksi antara manusia ada kesepakatan perilaku yang disetujui yang dapat mengantarkan kepada tujuan akhir dari maksud interaksi sosial tersebut. Bermain peran merupakan salah satu alat yang dapat mengacu kepada tercapainya kesepakatan tersebut. bukti nyata bahwa terjadi permainan peran dalam kehidupan manusia dapat dilihat pada masyarakat kita sendiri. Manusia menciptakan sebuah mekanisme tersendiri, dimana dengan permainan peran tersebut ia bisa tampil sebagai sosok- sosok tertentu. 
Sebagaimana pemikiran Blumer, pemikiran Goffman melihat masyarakat terdiri atas kehidupan yang diliputi oleh berbagai tingkah laku. Goffman selalu memandang bahwa perilaku keseharian dan interaksi tatap muka diibaratkan sama dengan panggung teater/drama. Perilaku saling melirik satu sama lain untuk kemudian berpaling lagi kearah lain menunjukkan bahwa orang-orang yang tidak saling mengenal itu menaruh kepercayaan untuk tidak saling mengganggu.

\section{Daftar Rujukan}

Al-shuaiby, A. 2009. Factors Contributing to Leadership Effectiveness Among Deans of Graduate Scholls of Educations. Dissertation Doctor of Education. The George Washington University.

Baker, G.A. 1998. Organizational Concept and Theories in the Public Sector. North Carolina State University: Raleigh, Mc.

Bartky, J.A. 1956. Administration an Educational Leadership. California: Stanford University Press

Basrowi, M. \& Soenyono. 2004. Teori Sosiologi Dalam Tiga Paradigma. Surabaya: Yayasan Kampusina.

Blumer H. 1969. Symbolik Interactionism Perspektif and Method. London: University of Calivornia Press Ltd.

Blumer H. 1969. Symbolik Interactionism Perspektif and Method.Englewood Cliffs, N.J. : Prentice- Hall, Inc.

Bounds, G. Et al. 1994. Beyond Total QualityManagement:Towards the Emerging Paradigm. New York : McnGraw-Hill, Inc. 
Brown, A 1998. Organization Culture. London: Pitman Publishing

Bryman, A. 2007. Research and Development Series Effektive Leadership in Higher education. London : Leadership Foundation of Higher Education.

Casman, K. 1998. Leadership From in Inside Out : Becoming A Leader from Life. Manneapolis, MN: Exscutive Excellence Publishing.

Daft. 2008. Strategic Leadership Making Corporate Plans Work. Woodhead - Faulkner Cambridge England.

Daresh, J. C. Playco, Marshal A. 1995. Supervision as a Proactive Process. Wayeland Press.

Denim, S. 2010.Kepemimpinan, Pendidikan: Kepemimpinan jenius (IQ + EQ), Etika, Perilaku Motivasi dan Mitos. Bandung: Alfabeta.

Denison, D.R. 1996. What is the Difference Between Organizational Culture and Organizational Climate? A Native's Point ofView A Decade Of Paragdigm Ward. Academy of Management Review, 21(3): 619-654

Denzin, N.K. 1992. Symbolic Interactionism and Cultural Studies the Politics of Interpretation. Malden: Blackwell publishing.

Esha, M.I. 2009. Institutisional Transformation: Reformasi dan Modernisasi Pendidikan Tinggi Islam. Malang: UIN Malang Press.

Etzioni, A. 1964. A Cooperative Analysis Of Complex Organizations. New York: FreePress.

Farida, E. 2009. Strategi Peningkatan Mutu Perguruan Tinggi Agama Islam (PTAI). Jurnal Edukasi, VII (3) : 29-69.

Fiedler, F.E. 1967. A Theory of Leader Effectiveness, New York: McGraw-Hill.

Freeman, S.J.R. \& Koehan, F.K. 2012.Academic Pathways to University Leadership President's Description Of Their Doctoral Educational. International Journal of Doctoral Studies, 7: 93-123.

Gardner, J.W. 1990. On Leadership. New York: The Free Press. 
Garfinkel, H. 1967. Studies in Ethno Methodology. Englewood Cliffs: Prentide Hall.

Ghafur, H.S. 2008. Manajemen Penjaminan Mutu Perguruan Tinggi di Indonesia: Suatu Analisis Kebijakan. Jakarta: PT. Bumi Aksara.

Giddens, A. \& Turner, J. 2008. Social theory Today. Diterjemahkan oeh Yudi Santoso. Yogyakarta: Pustaka Pelajar.

Goffman, E. 1956. The Presentation of Self in Everyday Life. Edinburgh : University of Edinburgh Sosial Science Research Centre.

Goffman, E. 1961. Asylums. New York: Doubleday Anchor Book.

Gordon, J.R. 1991. A Diagnostic Approach to OrganizationBeharvior. London: Allyin and Bacon

Hampton, D.R., Summer, C.E., \& Webber, R.A.1987. Organization Behavior and the Pratice of Management. Herper Collin: Gleinview,IL.

Harsono.2008. Model-model Pengelolaan Perguruan Tinggi: Perspektif Sosio-politik. Yogyakarta: Pustaka Pelajar.

Hatch, M.J. 1993. The Dynamic of Organizational Culture. Academy of Management Review, 18: 657- 693.

Hodge, B.J.\& W.P. Anthony. 1988. Organizational Theory ( $3^{\text {rd }}$ ed). Boston, Massachussets: Allyn and Bacon Inc.

Hoy, W.K. \& Miskel, L.G. 1987. Educational Administration: Theory, Research and Practce (Third Ed). New York: Radom House.

Immagart, G.1. Leadership and Leader Behavior in Handbook of Research Education Administration. London: Longman.

Kotter, J. 1990. A Force for Change How Leadership Differs from Management. New York: Free Press.

Kotter, J.P. \& Heskett J.L. 1992a. Corporate Culture and performance. New York: The Free Press. 
Kotter, J.P. \& J.L.. Heskelt. 1992.b. Dampak Budaya Perusahaan Terhadap Kinerja. Terjemah oleh Benyamin Molan. 1997. Jakarta: Prenhallindo.

Kottler, J. 1990. A Force for Change How Leadership Different from Management (First Edition). New York: Free Press.

Kouzez, J. \& Posner,B. 2007. The Leader Challenge. San Francisco: Jossey- Bass.

Kreitner, R. \& Knicki, A. 1992. Organizational Behavior. $2^{\text {nd }}$ Ed. Boston: IRWIN homowood,II.60430..

Mahmoed, i., Khan,S.B., Raziq, K.,\& Tahirkhcli. 2012. Role of Academic Leadership in Change Management for Quality in HigherEducation in Pakistan. Journal of Education and Practice, 3(16): 194-198.

Mead, G.H. 1934. Mind, Self And Society. Chanciago and London: University of Chicago Press.

Mead, G.H. 1934. Mind, Self And Society From the Standpoint of A Solid Behaviorist. Chicago and London: The University of Chicago Press.

Middlehurst, R. \& Elton, L. 1992. Leadership and Management in Higher Education. Studies in Higher Education, 17(3) : 251-264.

Muslimin, I. 2013. Pemimpin Perubahan Model Kepemimpinan Dalam Transisi Perubahan Kelembagaan. Malang: UIN Maliki Press.

Ndraha, T. 1988. Manajemen Perguruan Tinggi. Jakarta: Bina Aksara.

Owen, R.G. 1995. Organizational behaviour in Education. Boston: Ally and Boston.

Petton, M.Q. 1980. Qualitative Evaluation Metodhs. Beverly Hill, CA: Sage Publication, Inc.

Perkins, J.A. 1966. The University in Transtion. Princeton, New Jersey: Princton University Press.

Poloma, M.M. 2000. Sosiologi Kontemporer. Jakarta: Raja Grafindo Persada.

Ramsdan, P. 1998. Learning to Lead in Higher Education. London: Routledge. 
Ritzer, G. \& Goodman, DJ. 2003. Teori Sosiologi Moderen. Edisi Indonesia Terjemahan Alimandan. Jakarta: Kencana

Ritzer, G. 1983. Contemporary Sosiological Theory. New York: Alfreda Knopt.

Ritzer, G. 1992. Sosiology: A Multiple Paradigm Science. Alih Bahasa.

Robbins, S. 2003. Organizational behavior. New Jersey: Pearson Edocation.

Robbins, S.P. 1991. Organization behavior, $\left(5^{\text {th }}\right.$ ed). Englewood Cliffs, New Jersey: Prenticehall Inc.

Robert, M. 1991. The Essence of Leadership, Strategy Innovation and Decisivenness. Quorum Book.

Roberts, K.H. \& Hunt, D.M. 1994. Organization Behavior. Boston: PWS-Kent Publishing Company, International Student Edition.

Rowley. 1996. Motivation and Academic Staff in Higher Education. MCB University Press, 4(3): 11-16.

Sathye,M. 2004. Leadership in Higher Education, A Qualitative Study. Qualitative Social Research, 5.

Schein, E.H. 2002. Organizational Culture and Leadership, MT Sloan Management Review. (online) (http://www.tnellen.com/ted/tc/schein.html). Diakses 10 September 2014

Selznick, P. 1994. Leadership in administration A Socialogical Interpretation. Berkley, los Angeles, London: University of California Press.

Sergoivanni, T.J.1987. The Principalship: A Reflective Practice Perspective. Boston: allyn and Bacon, Inc.

Sergonivanni, T.J., M. Burlingame, F.S. Combs \& P.W. Thurston. 1987. Educational Governance and admininistration ( $2^{\text {nd }}$ ed). New York : Prentice Hall, Inc. 
Shamandi, E., Silang, A.D., Ismail, I.A., Samah, B.B.A., \& Otman, J. 2011. Competincies, Roles and Effective Academic Leadership in World Class University. International Journal of Business Administration,2(1) : 44-53

Siddique, M.A., Aslam, H.S Khan, M., \& Fatima M.U. 2011. Impact of Academic Leadership on Factulty's Motivation and Organizational Effectiveness in Hegher Education System. International Journal of Business and Social Science, 2(8): 184-191.

Siswanto\& Sucipto, A. 2008. Teori dan Perilaku Organisasi Sebuah Tinjauan Integratif. Malang; UIN Maliki Press.

Smircich, L. \& Morgan, G. 1982. Leadership The Management of Meaning. Journal of Applied behavior scince, 18: 257-273.

Sobirin, A. 2009. Budaya Organisasi: Pengertian, Makna dan Aplikasinya dalam Kehidupan Organisasi. Yogyakarta: Unit Penerbit dan Percetakan Sekolah Tinggi Ilmu Menajemen YKPN.

Soetopo, H. 2010. Perilaku Organisasi Teori dan Peraktek di Bidang Pendidikan. Bandung: PT. Remaja Rosdakarya

Sonhadji, A.K.H. 1990. Desain Dlam Pengembangan Institusi. Makalah Disajikan Pada Short Course Bagi Tenaga Fungsional Ackademik Perguruan Tinggi Di Semarang. Semarang, II-30 Juni.

Sonhadji, A.K.H. 1992. Sekilas Tentang Perguruan Tinggi di Indonesia. Makalah Disajikan Pada Semina Dalam Rangka Dies Natalis di Fakultas Hukum Universitas Brawijaya Malang. Malang, 14 Juli.

Sonhadji, Ahmad. Manusia, Teknologi Dan Pendidkan Menuju Peradaban Baru. Malang: UM Press.

Sulisworo, D, 2012. Model Kepemimpinan Moderen di Program Pascasarjana Universitas Ahmad Dahlan. Journal Of Education And Learning, 6(1) : 43-50. 
Suprayogo, I. \& Rasminto.2008. Perubahan Pendidikan Tinggi Islam: Refleksi Perubahan IAIN/STAIN Menjadi UIN. Malang: UIN Malang Press.

Terry, G.R. 1960. The Principles Of Management. Third Edition. Homework Illinois: Richard irwin.

Tosi, H.L. Mero, N.P. \& rizzo,J.H. 2005. Managing Organizational Behavior Utilizing Human Resources ( $9^{\text {th }}$ ed). London: Prentice-Hall Interntional Edition.

Trawler, P. 1997. Beyond the Robbin Trap: Reconceptualizing Academic Responses to Cange in Higher Education. Studies in Higher Education, 22: 301-318.

Usman, H 2010. Manajemen: Teori, Praktik, dan Riset Pendidikan. Jakarta: PT Bumi Aksara.

Veeger, K.J. 1985. Realitas Sosial: Refleksi Filsafat Sosial Atas Hubungan IndividuMasyarakat Dalam Cakrawala Sejarah Sosiologi. Jakarta: PT Gramedia.

Vicknes, T., Leask B. \& Ladyshewsky, R. 2009. Academic Fundamental Buiding Blocks. New South Wales: Australian Learnand Teaching Council.

Vilkinas, T\& Cartan, G. 2001 The Behavioral Conrol Room for Managers: The Integrator Role.

Leadership and Organization Development journal: 22(4): 175-185.

Vroom, V.H \& Yetton, P.w. !973. Leadership and Decision Making. Pittburgh: University of Pittsburgh Press.

Yuki, G.A. 2010. Leadership in Organization. New jersey: Prentice Hall. 